\title{
Effect of heat treatment on the mechanical properties of TiAl alloy
}

\author{
Jun Liu ${ }^{1, a}$, Yulan $\mathrm{Hu}^{1}$, Hongchao Qiao ${ }^{2}$ and Jibin Zhao ${ }^{2}$ \\ ${ }^{1}$ Shenyang Ligong University, Shenyang 110159, Liaoning, China \\ ${ }^{2}$ Shenyang Institute of Automation, Chinese Academy of Sciences, Shenyang 110016, Liaoning, China
}

\begin{abstract}
Heat treatment can influence the microstructure and mechanical properties, in order to homogenize the composition and microstructure, improve the mechanical properties, Ti44A16Nb0.9La alloy was heat treated at different temperatures and cooling conditions. The experimental results showed that macro-grains grew larger with the elevated temperature. The near-lamellar microstructure was obtained after heat treatment of $1200^{\circ} \mathrm{C}$ for 2 hours, which transformed into fully-lamellar microstructure as the temperature rose. In addition, linear and lumpish lanthanum compounds were located at inter-lamellae and the colony boundaries, which accumulated more with the accelerated temperature. Micro-hardness test indicated the value of micro-hardness increased differently and the value was the relative maximum when the temperature was $1270^{\circ} \mathrm{C}$, as a result of solution strengthening of $\mathrm{Nb}$ and precipitation strengthening of La.
\end{abstract}

Keywords: TiAl alloy; heat treatment; grain refining; micro hardness; lanthanum.

\section{Introduction}

TiAl based alloys are potential high-temperature structural materials with low density, high specific strength and excellent creep resistance at elevated temperature[1], while the poor room ductility and toughness markedly restricts its comprehensive applications in aero-engine fabrication and automotive filed. Alloying is an efficient way to improve the mechanical properties of TiAl based alloys by adding elements with high melting point, such as $\mathrm{Nb}$, which significantly enhances the strength, oxidation resistance and creep resistance at high temperature[2-3]. Moreover, B and Re addition can obviously suppress the growth of $\alpha$ grain [4-7] to refine the microstructure.

In addition, some studies [8-12] have reported that quenching, tempering and cyclic heat treatments do benefit to microstructure refinement and great performance of TiAl based alloys. It is reported by $\mathrm{He}$ [13] that the casting grain size of Ti48AI2Cr0.5Mo alloy is refined from $1000 \mu \mathrm{m}$ to $18 \sim 30 \mu \mathrm{m}$ by quenching and tempering treatments. According to $\mathrm{Du} \mathrm{H} \mathrm{[14],} \mathrm{the} \mathrm{yield} \mathrm{strength,} \mathrm{fracture}$ stress and ductility of as-cast structure is namely $330 \mathrm{MPa}, 415 \mathrm{MPa}$ and $0.7 \%$, which is increased to $660 \mathrm{MPa}, 825 \mathrm{MPa}$ and $3.3 \%$ respectively via cyclic heat treatment. Malinov S [15] reported that Ti46A12Cr2Nb alloy with fine fully lamellar microstructure by quenching, cyclic heat treatment and solution treatment successively, has an outstanding tensile stress of 707MPa.

${ }^{a}$ Corresponding author : lj-mail-sut@163.com 
Based on the above, this article mainly deals with the effect of heat treatment on the macro/microstructure and mechanical properties of Ti44Al6Nb0.9La alloy at different temperatures.

\section{Experimental: materials, procedures and detection methods}

The experimental alloy sample with a nominal composition of Ti44Al6Nb0.9La (at. \%) was prepared by vacuum non-consumed electric arc melting. On the basis of related references, different heattreatment processes were planned, namely of $1200^{\circ} \mathrm{C}$ for 2 hours/furnace cooling to $900^{\circ} \mathrm{C}$ /air cooling (HT1), $1270^{\circ} \mathrm{C}$ for 2 hours/furnace cooling to $900^{\circ} \mathrm{C}$ /air cooling (HT2), $1330^{\circ} \mathrm{C}$ for 2 hours/furnace cooling to $900^{\circ} \mathrm{C} /$ air cooling (HT3) with the heating rate of $10^{\circ} \mathrm{C} / \mathrm{s}$. In order to avert oxidization, samples were vacuum sealed and then put into the high-temperature vacuum furnace. After heat treatment macrostructure analysis was conducted with digital camera. The microstructure was characterized via scanning electron microscopy (SEM) employing back-scattered electron (BSE) imaging and optical microscopy $(\mathrm{OM})$ after alloy sample surface being distilled water cleaned, wind dried, and etched in Kroll's reagent of 5 vol. $\% \mathrm{HF}+5$ vol. $\% \mathrm{HNO}+90$ vol.\%H2O. Besides, phase composition was determined via the energy spectrum analysis (EDS) and micro hardness test was also performed.

\section{Results and discussion}

\subsection{The influence of heat treatment on the macrostructure of Ti44AI6Nb0.9La alloy}

Fig.1 showed the as-cast macrostructure and the macrostructure after heat treatment of Ti44Al6Nb0.9La alloy. Fine and uniform equaixed grains were obtained in the as-casting condition and grains grew significantly with the tendency of tiny grains being swallowed up after heat treatment. As shown in Table 1, the grain size of Ti44Al6Nb0.9La alloy augmented dramatically and the homogeneity of macrostructure deteriorated with the solution temperature rising because of simultaneous augmentation for colonies and grain size.
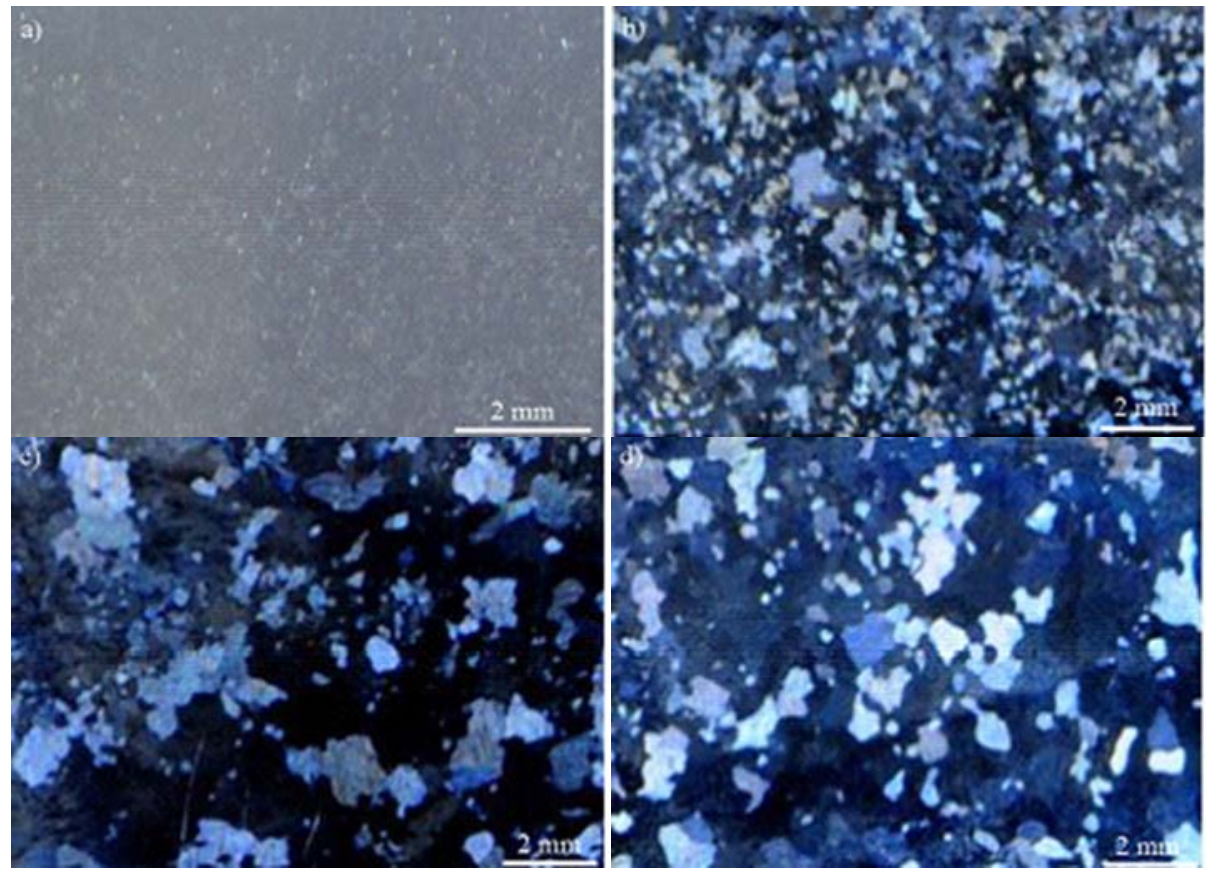

Figure 1. The macrostructure of Ti44Al6Nb0.9La: a) as cast, b) $1200^{\circ} \mathrm{C}$, c) $1270^{\circ} \mathrm{C}$, d) $1330^{\circ} \mathrm{C}$ 
Table 1. Average colonies size of Ti44Al6Nb0.9La alloy

\begin{tabular}{|c|c|c|}
\hline $\begin{array}{c}\text { Temperature( } \\
\left.{ }^{\circ} \mathrm{C}\right)\end{array}$ & $\begin{array}{c}\text { Grain size } \\
(\mu \mathrm{m})\end{array}$ & $\begin{array}{c}\text { Colonies size } \\
(\mu \mathrm{m})\end{array}$ \\
\hline 1200 & $380 \sim 460$ & $40 \sim 90$ \\
\hline 1270 & $640 \sim 950$ & $70 \sim 150$ \\
\hline 1330 & $850 \sim 1100$ & $180 \sim 300$ \\
\hline
\end{tabular}

\subsection{Effect of heat treatment on the microstructure of Ti44Al6Nb0.9La alloy}

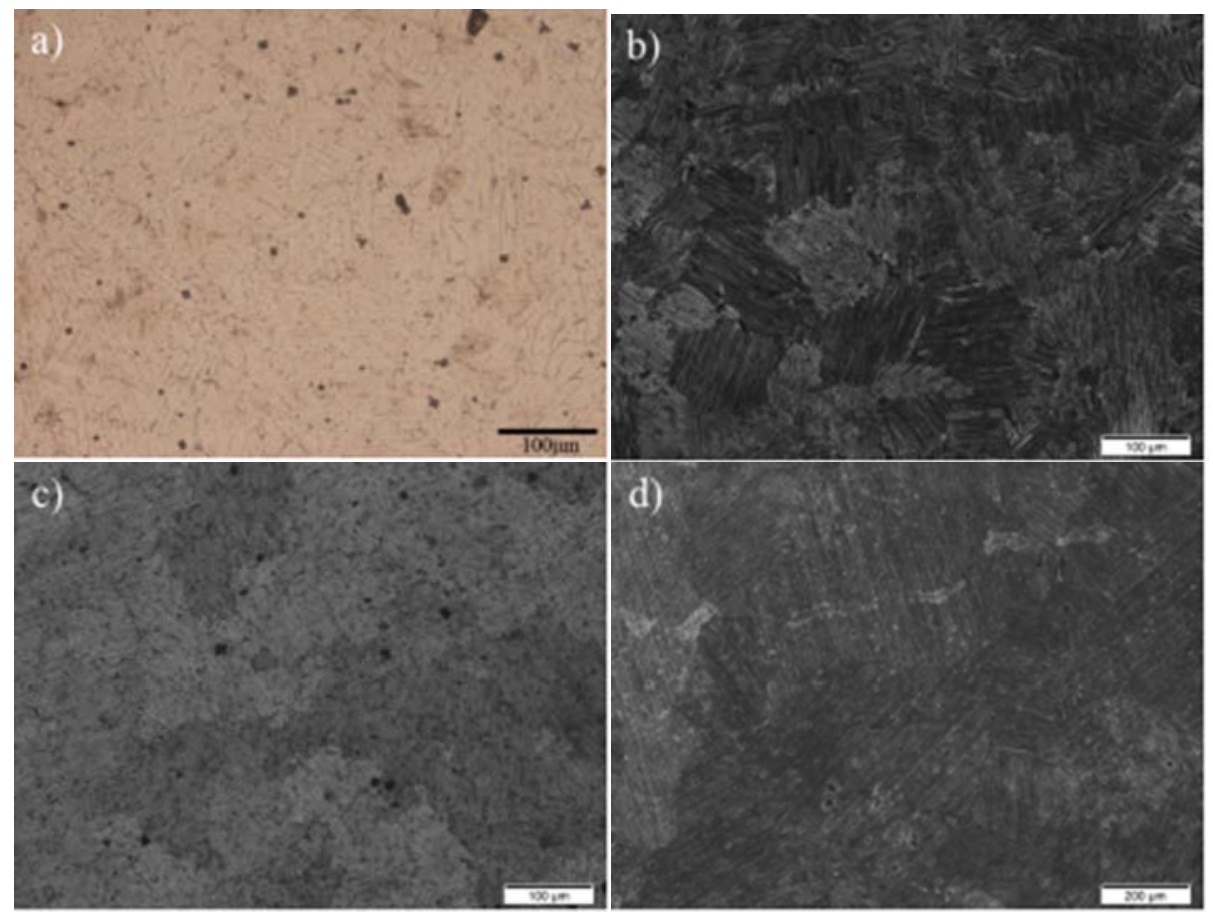

Figure 2. The microstructure of Ti44A16Nb0.9La by OM: a) as cast, b) $1200^{\circ} \mathrm{C}$, c) $1270^{\circ} \mathrm{C}$, d) $1330^{\circ} \mathrm{C}$

A typical duplex microstructure, consisting of primary $\gamma$ grains and $(\alpha 2+\gamma)$ lamellae, was observed in the as-casting Ti44Al6Nb0.9La alloy (Figure 2(a)), and a near-lamellar microstructure of about $380 \mu \mathrm{m}$ to $460 \mu \mathrm{m}$ in colony size was found after HT1 (Figure 2(b)). With the solution temperature elevated, the microstructure was transformed into a fully lamellar structure of $640 \mu \mathrm{m}$ to $950 \mu \mathrm{m}$ at $1270^{\circ} \mathrm{C}$ and $850 \mu \mathrm{m}$ to $1100 \mu \mathrm{m}$ at $1330^{\circ} \mathrm{C}$ in colony size. It was also observed that linear and lumpish black precipitations were distributed irregularly at inter-lamellae and the colony boundaries. In brief, the lamellar colonies and the amount of precipitation grew obviously with the solution temperature rising.

As shown in the Fig.3, lots of strip light phase appeared in the as-cast microstructure and then disappeared after heat treatment, which was proved as the segregation of $\mathrm{Nb}$ via EDS. Fig. 4 and Table 2 show that $\mathrm{Nb}$ was dissolved sufficiently into the matrix after heat treatment of $1330^{\circ} \mathrm{C}$ for 2 hours, which was in accordance with previous studies [16] that the segregation of $\mathrm{Nb}$ was removed by heat treatment. A large amount of granular, clubbed and lump light phase dispersed erratically and accumulated with the solution temperature increasing. EDS results replied that La was found free in 
the matrix and existed in the form of lanthanum compound, which exhibited lump, clubbed and granular shape and white contrast in BSE images.

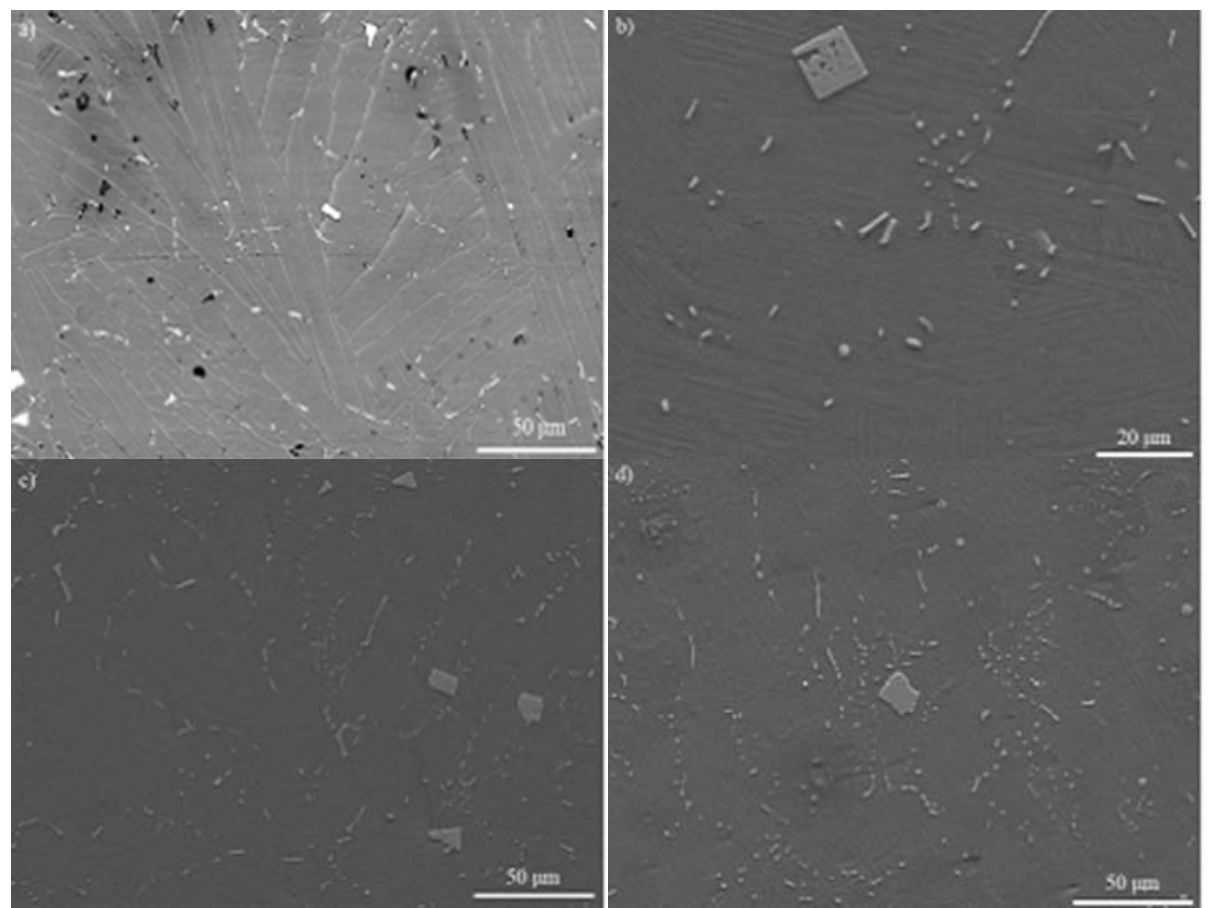

Figure 3. The microstructure of Ti44Al6Nb0.9La alloy by SEM a) as cast b) $\left.1200^{\circ} \mathrm{C} \mathrm{c)} 1270^{\circ} \mathrm{C} \mathrm{d}\right) 1330^{\circ} \mathrm{C}$

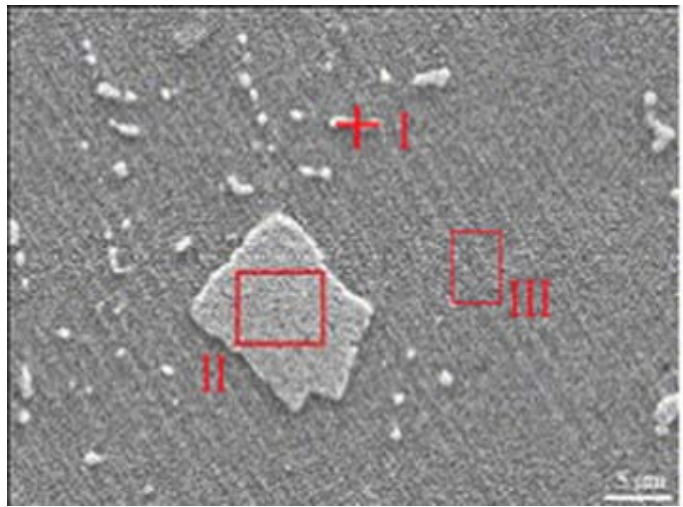

Figure 4. BSE image of Ti44Al6Nb0.9La alloy after heat treatment of $1330^{\circ} \mathrm{C}$

Table 2. Spectrum analysis of Ti44Al6Nb0.9La alloy at $1330^{\circ} \mathrm{C}$

\begin{tabular}{|c|c|c|c|c|c|}
\hline $\begin{array}{c}\text { Position } \\
\text { (at. \%) }\end{array}$ & $\mathrm{Ti}$ & $\mathrm{Al}$ & $\mathrm{Nb}$ & $\mathrm{La}$ & $\mathrm{O}$ \\
\hline $\mathrm{I}$ & 17.63 & 53.08 & 02.93 & 26.35 & - \\
\hline II & 06.37 & 21.26 & 00.37 & 22.11 & 49.89 \\
\hline III & 48.61 & 44.78 & 06.16 & 00.45 & - \\
\hline
\end{tabular}




\subsection{Effect of heat treatment on mechanical properties of Ti44AI6Nb0.9La alloy}

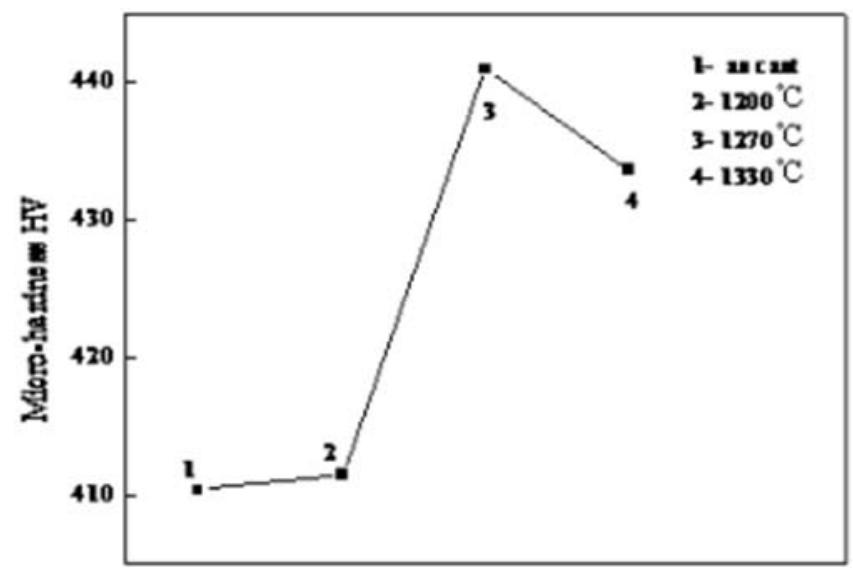

TIAA16Nb09La

Figure 5. The micro-hardness of Ti44Al6Nb0.9La alloy

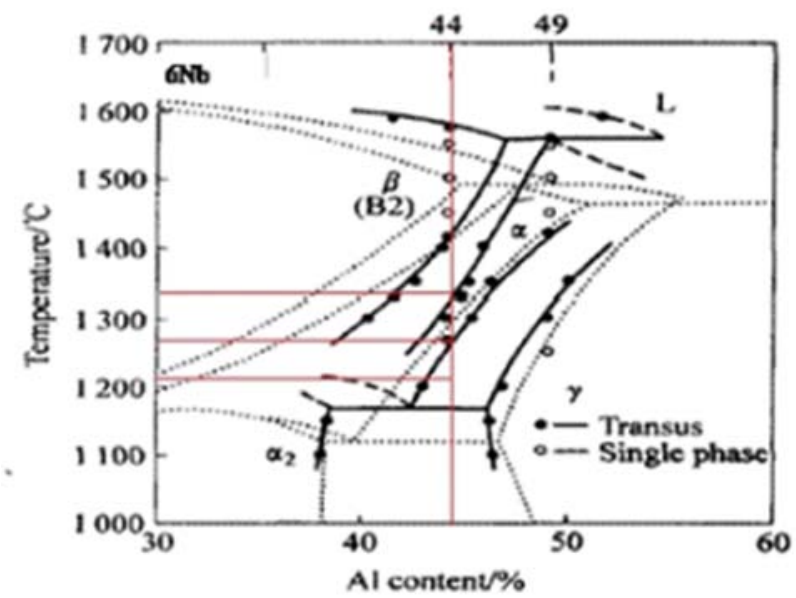

Figure 6. Binary phase diagram of Ti-Al-6Nb alloy

It was evident that the micro-hardness value improved differently after heat treatment as shown in Fig.5. Specifically, the micro-hardness increased slightly at $1200^{\circ} \mathrm{C}$ and the value increased significantly with the solution temperature rising and the micro-hardness value reached to the relative maximum at $1270^{\circ} \mathrm{C}$.

Owing to the segregation eliminated, $\mathrm{Nb}$ dissolved fully in the matrix after heat treatment and the solution strengthening was more significant at the elevated temperature with the result of high value of micro-hardness. After heat treatment of $1270^{\circ} \mathrm{C}$ for 2 hours, large quantity of Lanthanum compounds were located at the colony boundaries, which effectively suppressed the growth of lamellar colonies. As a result, the inter-crystalline strengthening of fine lamellar colonies had much to do with the highest micro-hardness. As depicted in the Binary phase diagram of Ti-Al-6Nb alloy (Fig.6), the heat treatment of $1330^{\circ} \mathrm{C}$ was located in the solid phase region of $(\alpha+\beta)$ close to the single phase region of $\alpha$, in which $\alpha$ grain grew dramatically. In conclusion, the coarse lamellar colonies decreased the micro-hardness relatively at $1330^{\circ} \mathrm{C}$. In a word, the micro-hardness improved after heat treatment with the comprehensive result of the solution strengthening of $\mathrm{Nb}$ and precipitation strengthening of La. 


\section{Conclusions}

(1) The grain size increased and the homogeneity of Ti44Al6Nb0.9La alloy deteriorated when the temperature was $1330^{\circ} \mathrm{C}$.

(2) Duplex transformed into NL by means of heat treatment of $1200^{\circ} \mathrm{C}$, while $(\alpha 2+\gamma) \mathrm{FL}$ was finally obtained after the heat treatment at $1270^{\circ} \mathrm{C}$ and $1330^{\circ} \mathrm{C}$, lump, clubbed and granular lanthanum compounds were found at inter-lamellar and the colony boundaries. With increasing of temperature, the amount of precipitation increased and the segregation of $\mathrm{Nb}$ was eliminated.

(3) In contrast with the as-cast structure, the micro-hardness values of Ti44Al6Nb0.9La alloy after different heat treatment processes were improved differently and the value reached to the relative maximum at $1270^{\circ} \mathrm{C}$, which was the comprehensive effect of solution strengthening of $\mathrm{Nb}$ and precipitation strengthening of La.

\section{Acknowledgements}

The authors are grateful to Prof. Hao Bo for his helpful discussions and advices. We would also like to thank the anonymous reviewers for their critical and constructive reviews of this paper. This study was co-supported by the National High Technology Research and Development Program of China (Grant No. 2012AA041310), the National Natural Science Foundation of China (Grant No: 61170146) and the Natural Science Foundation of Liaoning Province of China (Grant No. 2015020032).

\section{References}

1. K. Uenishi, K. F. Kobayashi, Intermetallics, 4, S95 (1996)

2. D. Hu, Intermetallics, 9, 1037 (2001)

3. Y.H. Wang, J.P. Lin, Y.H. He, Rare Metals, 25(4), 349 (2006)

4. U. Hecht, V. Witusiewicz, A. Drevermann, J. Zollinger, Intermetallics, 16, 969 (2008)

5. W.D. Wang, Y.C. Ma and B.Chen, J. Mater. Sci. Technol., 26(7), 639 (2010)

6. C.M. Liu, H.J. Li, Chinese Journal of Materials Research, 13(4), 395 (1999)

7. H.P. Qua, P. Li and S.Q. Zhang, Materials and Design, 31, 2201 (2010)

8. X.F. Ding, J.P. Lin, L.Q. Zhang, Trans. Nonferrous Met. Soc. China, 21, 26 (2011)

9. H. P. Qu, P. Li, S. Q. Zhang, A. Li, Materials and Design, 31, 2201 (2010)

10. J. Sienkiewicz, S. Kuroda, R. M. Molak, Intermetallics, 49, 57 (2014)

11. C. M. Liu, H. M. Wang, X. J. Tian, Materials Science \& Engineering A, 604, 176 (2014)

12. S.Z. He, Y.H. He, B.Y. Huang, Journal of Aero Nautical Materials, 3(23), 5 (2003)

13. D. Hu, R. R. Botten, Intermetallics, 10(7), 701 (2002)

14. S. MALINOV, W. SHA, Material Science and Engineering A, 365(2), 202 (2004)

15. W. Wang, W.D. Zeng, C. Xue, Intermetallics, 45, 29 (2014) 